\title{
Glycemic control of elderly patients with diabetes mellitus undergoing surgery: a mini review
}

\begin{abstract}
Overview: The risk of complications due to surgery is three times higher in the elderly compared to young adults; more than $50 \%$ of diabetic patients have a chance of undergoing surgery at least once in their life. Aging affects the metabolism and reduces physiological adaptive responses to physical stress, especially during the anesthetic-surgical procedures.
\end{abstract}

Objective: To analyze how the glycemic control of elderly patients with Diabetes Mellitus undergoing general surgery is done.

Method: an integrative review, conducted between May and June 2017, by two independent researchers, using modified Ursi protocol for selection of publications, in the electronic databases LILACS, Scielo and PubMed in Portuguese, English and Spanish languages was performed.

Results: 16 studies were identified for reading in full and three were selected for discussion, including 2420 participants. Glycemic control is based on the continuous measurement of capillary glycemia, and observation of the signs and symptoms of hyper and hypoglycemia, as well as the provision of adequate doses of insulin before, during and after surgery,

Conclusion: Only one study present a glycemic control protocol for using in adults and elderly people. We didn't identify protocols for glycemic control for surgical elderly, and few publications address the theme for this population.

Keywords: glycemic control, elderly, perioperative period, diabetes mellitus, type 2 , protocols
Volume 5 Issue I - 2018

\section{Cristina Scaloppi, Eliane da Silva Grazziano, Regimar Carla Machado \\ Department of Nursing, Federal University of São Carlos, Brazil}

Correspondence: Eliane da Silva Grazziano, Department of Nursing, Federal University of São Carlos, Brazil,Tel 551633 5I83 34, Email eligrazziano@gmail.com

Received: August 20, 2017| Published: January 24, 2018

\section{Introduction}

The elderly person presents a decline of the organic functions due to the organs and systems' aging, which generates greater difficulty to maintain the homeostasis during functional overload caused by morbid processes, surgical interventions or emotional changes experienced. With aging, the need for surgical interventions increases, as well as the use of a large number of drugs (polypharmacy) to control morbidities. ${ }^{1}$ Morbidites caused by chronic non-communicable diseases (NCDs) have been the main causes of death in the elderly population, following a worldwide trend. More than $50 \%$ of diabetic patients have a chance of undergoing surgery at least once in their lives. Diabetes mellitus(DM) is one of the main chronic diseases among the elderly, and the management of blood glucose during anesthesiasurgical procedure is necessary, mainly due to the metabolic disorders caused in this therapeutic procedure, among them the hyperglycemia and ketoacidosis. Perioperative hyperglycemia is aggravated when the patient is diabetic, requiring multi professional interventions for adequate glycemic control, avoiding the installation of ketoacidosis and hydro electrolytic imbalance. ${ }^{2}$ Study identified hyperglycemia in $40 \%$ of patients admitted to hospitals, half of whom were not diabetic, corroborating the relationship between physical and emotional stress, use of corticosteroids and anti-inflammatories with hyperglycemia. Evidence indicates that perioperative hyperglycemia significantly increases the risk for pneumonia, systemic blood infections, urinary tract infection, skin infections, and acute postoperative renal failure in adult patients undergoing general surgery. There is a positive association between blood glucose concentration and mortality rate, as well as the association between increased days of hospitalization and risk for complications and mortality in patients with glycemia $>150 \mathrm{mg} / \mathrm{dl}$, especially in non-diabetic patients. ${ }^{4}$ The intra operative period presents a number of factors that affect blood glucose such as surgical stress and use of anesthetic drugs. Therefore, a protocol for the postoperative period may not be effective. For an algorithm to be really effective it would be necessary to use frequent measures of blood glucose for the patient or certain type of surgery and to be able to adapt its parameters to the various conditions during this period. ${ }^{5}$ This integrative review (IR) aimed to identify and analyze protocols for the glycemic control of elderly patients with Diabetes Mellitus undergoing general surgery.

\section{Discussion}

The main question for this IR was "Which glycemic control protocol is most used for the treatment of diabetic elderly patients undergoing surgery?". To search and selection of the studies, we used the PubMed, Lilacs and Scielo databases using a modified Ursi protocol ${ }^{6}$ with keywords, and the MESH terms "Perioperative Management" AND "Glucose" OR "Perioperative Glucose Management" OR "Glucose Management" AND "Perioperative" AND "Insulin", conducted between May and June 2017, by two independent researchers. Publications were included in Portuguese, English, and Spanish, with abstracts and texts available in full, without temporal limitation. Exclusion criteria were studies of literature review, conducted with children, qualitative studies, manuals and guides, thesis and dissertations. We identified 16 articles, and after 
reading in full, three articles were selected, all published in the United States between 2013 and 2015. Only one study $^{7}$ was performed exclusively with elderly patients undergoing elective outpatient surgeries $(\mathrm{N}=268)$ with general anesthesia, an average of $67(\mathrm{SD}=11)$ years. Two studies included adults in their series, and another ${ }^{8}$ of the 279 participants, 121 were surgical patients, with an average of 60.1 $(\mathrm{SD}=11 ; \mathrm{CI}=18-80)$ years. A study ${ }^{5}$ presented an institutionalized protocol for the management of perioperative glycemia with a sample of 1,873 , but with a mean age of $58.7(\mathrm{SD}=13.7)$ years.

Studies identified in this IR showed a total of 2,420 participants, with a mean age of 61.9 years, showing that the younger diabetic patients are more frequently submitted to surgeries. Epidemiological studies of developed countries conducted two decades ago indicated that $30 \%$ of hospital beds are occupied by the elderly, and these are submitted to $50 \%$ of emergency surgeries corresponding to $75 \%$ of perioperative deaths. ${ }^{9}$ In the only randomized clinical trial identified, ${ }^{8} 121$ surgical patients with type 2 diabetes, and a mean age of $60.1(\mathrm{SD}=11 ; \mathrm{CI}=18$ 80 ) were orthopedic, abdominal and urological surgeries. Regardless of the morbidity, the decomposition of the associated diseases, among them diabetes mellitus and systemic arterial hypertension, aggravate the operative situation and are potential factors for postoperative complications. ${ }^{10}$

The Sliding-Scale Insulin Therapy protocol (SSIT) ${ }^{8}$ was applied for patients with blood glycemia from $140 \mathrm{mg} / \mathrm{dl}$, and consisted of bolus administration of long-acting Glargine insulin once daily, Glulisine insulin before meals and Glulisine correction doses according to prebrand glycemia, after monitoring of capillary glycemia. The results indicated good glycemic control and better response of surgical patients when compared to clinical patients. Evidences indicate that intensive glycemic control in the elderly reduces the complications such as acute renal failure, septicemia and the need for blood transfusion. ${ }^{11}$

SSIT protocol ${ }^{8}$ should be applied with glycemic rates between $100-140 \mathrm{mg} / \mathrm{dl}$; recommends initiating glycemic management for all diabetic and non-diabetic patients with elevated blood glucose $>140 \mathrm{mg} / \mathrm{dL}$; control blood glucose level; use the correction table according to the glucose level and rate of level changes with infusion of intravenous insulin; administer a low dose of dextrose during insulin infusion to minimize the risk of hypoglycemia, and the occurrence of catabolic effect.

A prospective study with 1,873 participants using the University of Washington protocol ${ }^{5}$ did not identify improved parameters for glycemic management. It is not clear how effective the algorithms for glycemic management during the intra operative period are. The protocol recommends initiating glucose management for all diabetic and non-diabetic patients with blood glucose levels equal to or greater than $140 \mathrm{mg} / \mathrm{dL}$, and it's applied to diabetic patients, being the first measure of glucose performed before the surgical incision. Depending on the level of glucose and type diabetes (Type 1 or 2), an initial dose of insulin is applied according to a table, then hourly glucose measurements are performed. For each new glucose measure, based on the change in glucose level of the previous one, a new algorithm is determined by the protocol table. Using the new glucose level algorithm, a new dose of insulin is applied. In a retrospective review of 268 elderly patients (mean age of $67(\mathrm{sd}=11)$ years), patients with type $2 \mathrm{DM}$, used a protocol with blood glucose measurement in the pre, intra and postoperative periods, and administration of insulin in the postoperative period (anesthesia recovery). The study did not allow concluding what was the level of intra operative glycemic control or efficacy of hyperglycemia management in these patients. ${ }^{12}$

\section{Conclusion}

Aging affects metabolism, and reduces physiological responses adaptive to physical stress, including anesthetic-surgical procedure. Thus, care for the elderly patient undergoing surgeries should be differentiated in face of possible complications in the postoperative period. We identified a lack of effective protocols for the adequate management of diabetes mellitus in elderly population. Randomized clinical trial that applied Glargine and Glulisine insulin, and the SSIT protocol presented the best results in the glycemic control. There was a difference in insulin response in surgical and Patients with type $2 \mathrm{DM}$, whereas clinical patients had a significant increase in blood glucose concentration and concentration of glycated hemoglobin when compared to surgical patients. Glycemic control is based on the continuous measurement of capillary glycemia, and observation of signs and symptoms of hyper and hypoglycemia, as well as the provision of adequate doses of insulin before, during and after surgery, activities that are shared by the nursing team. The knowledge of DM management protocols is a fundamental factor for the success of glycemic control, reduction of complications and promotion of postoperative rehabilitation. As a recommendation it is suggested to carry out clinical studies that evaluate the effectiveness of protocols for glycemic management in the perioperative period for the elderly with the participation of the multidisciplinary team.

\section{Acknowledgement}

None.

\section{Conflict of interest}

The author declares no conflicts of interest.

\section{References}

1. Associação brasileira de enfermeiros de centro cirúrgico, Recuperação anestésica e centro de material e esterilização. Práticas Recomendadas da SOBECC. Manole, São Paulo, Brazil: Springer; 2013. 369 p.

2. Sociedade brasileira de diabetes. Diretrizes da Sociedade Brasileira de Diabetes 2014-2015. AC Farmacêutica, São Paulo, Brazil: Springer; 2015. $374 \mathrm{p}$.

3. Umpierrez GE, Isaacs SD, Bazargan N, et al. Hyperglycemia: An independent marker of in-hospital mortality in patients with undiagnosed diabetes. J Clin Endocrinol Metab. 2002;87(3):978-982.

4. Frisch A, Chandra P, Smiley D, et al. Prevalence and clinical outcome of hyperglycemia in the perioperative period in noncardiac surgery. Diabetes Care. 2010;(33):1783-1788.

5. Nair BG, Grunzweig K, Peterson GN, et al. Intraoperative blood glucose management: impact of a real-time decision support system on adherence to institutional protocol. J Clin Monit Comput. 2015;30(3):301-312.

6. Ursi ES. Prevenção de lesões de pele no perioperatório: revisão integrativa da literature $128 \mathrm{f}$. Dissertação (Mestrado em Enfermagem) - Escola de enfermagem de ribeirão preto, Universidade de São Paulo, Ribeirão Preto, Brazil: Springer; 2005.

7. Smiley D, Umpierrez GE, Hermayer K, et al. Differences in inpatient glycemic control and response to subcutaneous insulin therapy between medicine and surgery patients with type 2 diabetes. $J$ Diabetes Complications. 2013;27(6):637-641. 
8. Creditor MC. Hazards of hospitalization of the elderly. Ann Inter Med. $1993 ; 118(3): 219-223$

9. Colégio Brasileiro de Cirurgiões. Programa de Auto avaliação em cirurgia - Paciente Idoso. Ano 2. Fascículo II. Rio de Janeiro: Diagraphic Editora, São Paulo, Brazil: Springer; 2012.
10. Vendites S, Almada-Filho CM, Minossi JG. Aspectos gerais da avaliação pré-operatória do paciente idoso cirúrgico. ABCD Arq Bras Cir Dig. 2010;23(3):173-182.

11. Coan KE. Perioperative Management of patients with diabetes undergoing ambulatory elective surgery. J Diabetes Sci Technol. 2013;7(4):983-989. 